\title{
Thermal properties of wood-based panels: thermal conductivity identification with inverse modeling
}

\author{
Lukasz Czajkowski $^{1} \cdot$ Wiesław Olek $^{1} \cdot$ Jerzy Weres $^{2} \cdot$ Ryszard Guzenda $^{1}$
}

Received: 7 November 2014/Published online: 25 February 2016

(C) The Author(s) 2016. This article is published with open access at Springerlink.com

\begin{abstract}
Accuracy and effectiveness of predicting the heat transfer in wood-based panels is increasingly important for describing their behavior, especially for varying environmental conditions. To model the heat transfer in wood-based panels it is essential to input credible data on their thermal properties. Therefore, proper estimation of the specific heat and thermal conductivity is fundamental. A finite element inverse analysis procedure was developed. The procedure was designed in such a way that anisotropy of the thermal conductivity was accounted for. For all analyzed wood-based panels, in-plane thermal conductivity was significantly higher compared to the transverse one, and it was recommended to consider the anisotropy, and to use both in-plane and transverse thermal conductivity for modeling heat transfer. The effect of temperature on thermal conductivity was not clearly manifested. The thermal conductivity values were decreasing or increasing with temperature. In some cases this influence was practically insignificant (i.e. OSB), while for low density fiberboard the effect of temperature on thermal conductivity was the highest. The identification procedure was validated and its credibility was assessed. It was shown that data on thermal properties available in the literature should not be recommended to model the heat transfer.
\end{abstract}

Łukasz Czajkowski

lukasz.czajkowski@up.poznan.pl

1 Faculty of Wood Technology, Poznań University of Life Sciences, ul. Wojska Polskiego 28, 60-637 Poznań, Poland

2 Faculty of Agriculture and Bioengineering, Poznań University of Life Sciences, ul. Wojska Polskiego 28, 60-637 Poznań, Poland

\section{Introduction}

The importance of accurate and effective prediction of heat transfer processes in wood-based panels is increasing with respect to describing in-service behavior of the panels, especially for varying environmental conditions. Another problem related to heat transfer modeling is linked with manufacturing processes of the panels, mainly due to the importance of the cooling phase. The heat transfer prediction requires among others credible data on thermal properties of investigated materials. Therefore, proper estimation of the specific heat and the thermal conductivity may be essential for increasing accuracy of predictions. The problem of the specific heat measurements of woodbased panels has already been discussed in a previous study and new results of the property have been delivered (Czajkowski et al. 2016). Data describing the thermal conductivity, obtained 40 and 50 years ago (e.g. Ward and Skaar 1963; TenWolde et al. 1988), are still frequently applied to heat transfer modeling, in spite of the fact that traditional experimental methods for determining the data are not capable of dealing with dependency of the properties on temperature.

The steady-state method was most often applied when determining the thermal conductivity of wood-based panels. Although different modifications of experimental setups had been made, the guarded hot plate apparatus (e.g. Speyer 1994; Sonderegger and Niemz 2009) and the heatflow meter apparatus (e.g. Kamke and Zylkowski 1989; Kawasaki and Kawai 2006) were the ones most often applied. However, the application of the hot plate apparatus required several methodological assumptions, which imposed performing measurements in the steady-state for absolutely dry and isotropic materials. Moreover, the thermal conductivity values were assigned to the average 
temperature of heater and cooler surfaces. The perfect contact of the examined material with the heater and cooler surfaces had to be assumed (e.g. Bučar and Straže 2008). The assumption is hardly satisfied in the case of woodbased panels, which implies a serious inaccuracy of the measurements. The application of the steady-state method makes it impossible to account for the thermal conductivity anisotropy and the property dependence on temperature. Despite the serious restriction of the application of the steady-state method, the guarded hot plate apparatus is often used to determine the thermal conductivity of woodbased panels as a function of moisture content (e.g. Sonderegger and Niemz 2012), temperature (e.g. Vololonirina et al. 2014) and directions of heat conduction (Schneider and Engelhardt 1977).

Another problem related to the hot plate apparatus application is attaining the steady-state for the heat conduction, which is usually considered as hard or even impossible to be obtained (Lewis 1967). This problem as well as long measurements time induced the development of alternative transient methods for determining the thermal conductivity. The principle merit of the transient methods is a relatively short duration of the experiments (Asako et al. 2002) as well as measurements for samples of different shapes. The short time of experiments has a special importance in the case of measurements of moist materials as it reduces water transfer in samples and improves accuracy of measurements. The thermal conductivity measurements with the application of the hot wire, hot strip or transient plane source (e.g. Asako et al. 2002; Gobbé et al. 2004; Kotlarewski et al. 2014) are associated with serious problems related to the determination of the amount of heat emitted by a heating element as well as the reduction of the contact resistance at the interface between a heating element and the examined material (Hammerschmidt and Sabuga 2000).

Recently, Zhou et al. (2013) applied the light flesh method to measure thermal diffusivity of commercial MDF for three levels of moisture content and six different values of temperature. The obtained results were used to calculate thermal conductivity values. The property was determined for the transverse direction. However, the obtained dependence of the thermal conductivity on temperature was ambiguous. Another study on the thermal properties of commercial MDF was presented by Li et al. (2013). The thermal conductivity was measured with the transient plane source method and hot plate method. The obtained results clearly showed that the methods should not be applied to commercial wood-based panels which are characterized by the density profile in the transverse direction.

The inaccurate values of the thermal properties imply significant errors of heat transfer modeling. The problem has already been discussed for solid wood in Olek and
Guzenda (1995), Weres et al. (2000), Olek et al. (2003). The complexity and susceptibility to errors of the direct measurement methods for determining thermal properties of wood-based panels result in severe uncertainty of predictions of heat transfer processes in such modern materials. An alternative approach was used in the present study in order to improve accuracy of the thermal conductivity determination. The approach was based on the computeraided heat transfer inverse analysis applied to identify the unknown or uncertain thermal properties (Alifanov 1994; Isakov 1998; Kirsch 1996; Weres et al. 2000; Weres and Olek 2005). Therefore, the objective of the paper was to develop a finite element inverse analysis procedure for estimating the thermal conductivity in principal directions of the wood-based panels.

\section{Methods}

\subsection{Experimental data}

Experimental material was obtained from the following wood-based panels: (a) commercial three layer particleboard of a thickness of $18 \mathrm{~mm}$ and mean oven dry density of $634 \mathrm{~kg} / \mathrm{m}^{3}$ (coded as PB1), (b) normal density laboratory-made one-layer particleboard of reduced density profile of a thickness of $26 \mathrm{~mm}$ and mean oven dry density of $754 \mathrm{~kg} / \mathrm{m}^{3}$ (coded as PB2), (c) high density laboratorymade one-layer particleboard of reduced density profile of a thickness of $10 \mathrm{~mm}$ and mean oven dry density of $973 \mathrm{~kg} / \mathrm{m}^{3}$ (coded as PB3), (d) laboratory-made one-layer low density fiberboards of a thickness of $20 \mathrm{~mm}$ and mean oven dry density of $256 \mathrm{~kg} / \mathrm{m}^{3}$ (coded as LDF), (e) commercial oriented strand boards of a thickness of $15 \mathrm{~mm}$ and mean oven dry density of $619 \mathrm{~kg} / \mathrm{m}^{3}$ (coded as OSB). The material was firstly equilibrated under laboratory conditions. Sheets of individual materials were used to form the samples in a shape of cubes. The dimensions of edges of the cubes were in the range of $118-182 \mathrm{~mm}$. Five thermocouples were mounted in selected locations of each sample. Moreover, two additional thermocouples were installed on the surfaces of the samples. A general scheme of a sample is presented on the left in Fig. 1. Each sample had three principle planes of symmetry, which are also presented in the scheme. It was assumed that the origin of the orthocartesian system of coordinates was located at the front bottom left corner of a sample. The locations of the mounted thermocouples are also schematically depicted on the right of Fig. 1. The coordinates of the thermocouples locations are listed in Table 1 separately for each investigated sample.

During transient heat transfer experiments individual samples were firstly heated in order to obtain a uniform 
Fig. 1 Sample for transient heat transfer experiments with depicted principle symmetry planes (left) and locations of thermocouples mounted inside the investigated material (right)

Table 1 Coordinates of the thermocouples locations in $\mathrm{mm}$
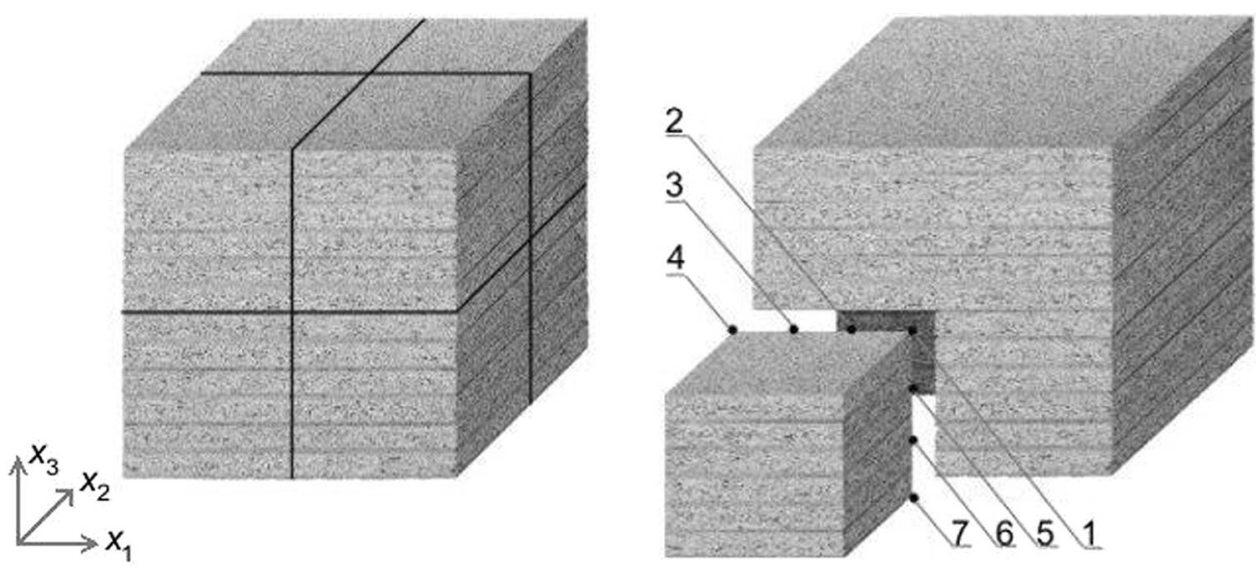

\begin{tabular}{llllllll}
\hline Codes & \multicolumn{7}{l}{ Thermocouples location } \\
\cline { 2 - 8 } & $\# 1$ & $\# 2$ & $\# 3$ & $\# 4$ & $\# 5$ & $\# 6$ & $\# 7$ \\
\hline PB1 & $80 ; 80 ; 80$ & $53 ; 80 ; 80$ & $26 ; 80 ; 80$ & $0 ; 80 ; 80$ & $80 ; 80 ; 53$ & $80 ; 80 ; 26$ & $80 ; 80 ; 0$ \\
PB2 & $84 ; 84 ; 84$ & $51 ; 84 ; 84$ & $31 ; 84 ; 84$ & $0 ; 84 ; 84$ & $84 ; 84 ; 51$ & $84 ; 84 ; 31$ & $84 ; 84 ; 0$ \\
PB3 & $72 ; 72 ; 72$ & $36 ; 72 ; 72$ & $18 ; 72 ; 72$ & $0 ; 72 ; 72$ & $72 ; 72 ; 36$ & $72 ; 72 ; 18$ & $72 ; 72 ; 0$ \\
LDF & $59 ; 59 ; 59$ & $60 ; 59 ; 59$ & $20 ; 59 ; 59$ & $0 ; 59 ; 59$ & $59 ; 59 ; 40$ & $59 ; 59 ; 20$ & $59 ; 59 ; 0$ \\
OSB & $90 ; 91 ; 90$ & $60 ; 91 ; 90$ & $30 ; 91 ; 90$ & $0 ; 91 ; 90$ & $90 ; 91 ; 61$ & $90 ; 91 ; 31$ & $90 ; 91 ; 0$ \\
\hline
\end{tabular}

distribution of the initial temperature inside the investigated material. Then the cooling phase started, and the temperature measurements were collected by a data acquisition system every $300 \mathrm{~s}$ with automatic data logging in the empirical database. An example of empirical data obtained during the cooling phase of a sample is presented in Fig. 2. The results were used in the process of thermal conductivity identification. The other sets of empirical data registered during heat transfer processes were applied to

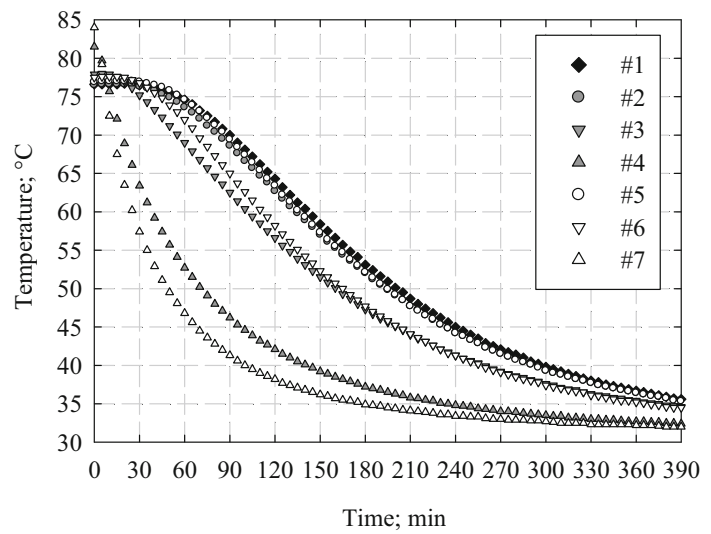

Fig. 2 Experimentally determined temperature changes as a function of time by sensors (thermocouples) \#1, \#2, \#3, \#4, \#5, \#6 and \#7 as obtained for the cooling phase of a transient heat transfer experiment made for laboratory-manufactured high density particleboard (code PB2) validate the identified coefficients of the mathematical model of the process.

\subsection{Mathematical model of transient heat transfer}

The mathematical model of the transient, three-dimensional, quasi-linear heat transfer problem in anisotropic materials is given by the quasi linear partial differential equation:

$c \rho \frac{\partial t}{\partial \tau}=\nabla(k \nabla t), \quad(\mathbf{x}, \tau) \in \Omega \times\left(0, \tau_{F}\right]$

with the initial condition

$t(\mathbf{x}, 0)=t_{0}(\mathbf{x}), \quad(\mathbf{x}) \in \Omega$

and the first kind boundary condition

$t(\mathbf{x}, \tau)=t_{s}(\mathbf{x}), \quad(\mathbf{x}, \tau) \in \partial \Omega^{I} \times\left(0, \tau_{F}\right]$.

The temperature influence on the thermal conductivity values was also accounted. Therefore, two options of the thermal conductivity parameterization were considered:

$k=a$;

$k=a+b \cdot t$.

\subsection{Inverse identification}

The operational form of the transient heat transfer model (1)-(5) was obtained by the application of the finite 
element method. The solution of the direct transient heat transfer problem resulted in calculating temperature values at positions consistent with the locations of the mounted thermocouples and for each time instant of the investigated processes. The calculated temperature values were compared to the measured values in the transient heat transfer experiments. It enabled determining values of the objective function $(S)$ which was defined as the sum of the squares of the residuals of the measured and predicted values of temperature:

$S=\sum_{i=1}^{N T} w_{i}\left[t_{\text {exp }}\left(\tau_{i}\right)-t_{\text {pred }}\left(\tau_{i}\right)\right]^{2}$.

The objective function values were minimized with the use of the optimization procedure based on the trust region algorithm combined with the secant-updating quasiNewton procedure to approximate the Hessian (Weres et al. 2009). The inverse identification approach was implemented and coded in Lahey/Fortran 95 environment. As the number of time intervals $(N T)$ was different for the analyzed heat transfer processes, the normalized objective function $(S N)$ was defined to compare the effectiveness of the identification:

$S N=\frac{S}{N T \cdot N S}$,

where $N S$ denotes number of sensors (thermocouples).

\section{Results}

Although the inverse modeling is an effective method for the identification of materials properties it reveals a serious drawback when applying the method to simultaneous determination of the specific heat and the thermal conductivity. Huang and Yan (1995) stated that the arbitrarily selected initial values of the properties led to obtaining the infinite number of pairs of the coefficients to be sought. It was observed for the same values of the objective function minimum. Therefore, Huang and Yan (1995) suggested that the identification should exploit credible data of one of the properties, i.e. the specific heat or the heat conductivity. Kim et al. (2003) used the experimentally determined specific heat values for the inverse identification of the thermal conductivity of anisotropic composite material. A similar approach was used by Monteau (2008) for sandwich bread. The specific heat was firstly measured with a DSC system, and the obtained results were used for the inverse identification of the thermal conductivity as a function of temperature. The present study exploited the same methodology and the results of the specific heat measurements as reported by Czajkowski et al. (2016) were used for determining the thermal conductivity with the inverse method.

It was assumed that due to the space orientation of strands, particles or fibers in wood-based panels, the inplane thermal conductivities have to be similar and it was postulated in the present study to regard the in-plane values of the property as equal. Therefore, the identification comprised finding the in-plane thermal conductivity and the transverse thermal conductivity which were parameterized by Eqs. (4) and (5). It resulted in finding a constant, independent of temperature, value of the property as well as the thermal conductivity values being the linear function of temperature. The results of the identification as obtained for five analyzed wood-based panels are presented in Table 2. The values of the coefficients $a$ and $b$ were supplemented by the objective function $(S)$ and the normalized objective function $(S N)$. It enabled to estimate the influence of temperature on the thermal conductivity. The most significant temperature influence was found for LDF as the $S N$ values were reduced 6 times when introducing the linear dependence on temperature (Table 2).

The identified results of the thermal conductivity were compared to the data available in the literature. It was assumed that the comparison was made for the same type of wood-based panels of similar density, i.e. for OSB (Fig. 3) and particleboard coded as PB1 (Fig. 4). The data provided for OSB by Kawasaki and Kawai (2006) did not account for anisotropy and temperature influence. Moreover, the identified values of the in-plane and transverse thermal conductivity were much higher than the data reported by Kawasaki and Kawai (2006). In the case of particleboard, Sonderegger and Niemz (2009) considered the temperature influence on the thermal conductivity data obtained for the transverse direction. The reported temperature influence was considered in the range of $10-30^{\circ} \mathrm{C}$ (Fig. 4), and the discussed values of the thermal conductivity were similar to the ones identified in the present study for the transverse direction. The anisotropy of the thermal conductivity was also studied by $\mathrm{Li}$ et al. (2013). The measurements were made for the center and surface layers of commercial MDF. It was found that for the center layer with a density of ca. $600 \mathrm{~kg} / \mathrm{m}^{3}$ the in-plane thermal conductivity was approximately twice as high as in the transverse direction, while for the surface layer of the density of ca. $950 \mathrm{~kg} / \mathrm{m}^{3}$ the thermal conductivity values were almost equal for both directions.

Unfortunately, the comparison of the thermal conductivity data, as presented above, cannot deliver information on the reliability of the discussed properties. The only procedure for the assessment of the values is related to their validation, i.e. using the data for modeling heat conduction and comparing the calculated temperature values to the ones obtained in experiments. 
Table 2 Values of the coefficients estimated by the inverse modeling

\begin{tabular}{|c|c|c|c|c|c|c|c|c|}
\hline \multirow[t]{2}{*}{ Codes } & \multirow[t]{2}{*}{ Direction of heat conduction } & \multirow[t]{2}{*}{ Empirical model } & \multicolumn{2}{|c|}{ Identified coefficients } & \multirow[t]{2}{*}{$S$} & \multirow[t]{2}{*}{ NT } & \multirow[t]{2}{*}{ NS } & \multirow[t]{2}{*}{ SN } \\
\hline & & & $a$ & $b$ & & & & \\
\hline \multirow[t]{4}{*}{ PB1 } & \multirow[t]{2}{*}{ Transverse } & Equation (4) & 0.1130 & - & 291 & 240 & 5 & 0.24 \\
\hline & & Equation (5) & 0.1075 & 0.00004645 & 113 & & & 0.09 \\
\hline & \multirow[t]{2}{*}{ In-plane } & Equation (4) & 0.2835 & - & 291 & & & 0.24 \\
\hline & & Equation (5) & 0.3593 & -0.0008751 & 113 & & & 0.09 \\
\hline \multirow[t]{4}{*}{ PB2 } & \multirow[t]{2}{*}{ Transverse } & Equation (4) & 0.1273 & - & 95 & 72 & 5 & 0.26 \\
\hline & & Equation (5) & 0.2191 & -0.001000 & 35 & & & 0.10 \\
\hline & \multirow[t]{2}{*}{ In-plane } & Equation (4) & 0.2941 & - & 95 & & & 0.26 \\
\hline & & Equation (5) & 0.1577 & 0.001599 & 35 & & & 0.10 \\
\hline \multirow[t]{4}{*}{ PB3 } & \multirow[t]{2}{*}{ Transverse } & Equation (4) & 0.1955 & - & 34 & 72 & 5 & 0.10 \\
\hline & & Equation (5) & 0.3836 & -0.002048 & 20 & & & 0.06 \\
\hline & \multirow[t]{2}{*}{ In-plane } & Equation (4) & 0.3849 & - & 34 & & & 0.10 \\
\hline & & Equation (5) & 0.2624 & 0.001347 & 20 & & & 0.06 \\
\hline \multirow[t]{4}{*}{ LDF } & \multirow[t]{2}{*}{ Transverse } & Equation (4) & 0.03518 & - & 1162 & 60 & 5 & 3.87 \\
\hline & & Equation (5) & -0.01049 & 0.0006215 & 189 & & & 0.63 \\
\hline & \multirow[t]{2}{*}{ In-plane } & Equation (4) & 0.09802 & - & 1162 & & & 3.87 \\
\hline & & Equation (5) & -0.008881 & 0.001265 & 189 & & & 0.63 \\
\hline \multirow[t]{4}{*}{ OSB } & \multirow[t]{2}{*}{ Transverse } & Equation (4) & 0.1672 & - & 160 & 360 & 5 & 0.09 \\
\hline & & Equation (5) & 0.2154 & -0.0006215 & 82 & & & 0.05 \\
\hline & \multirow[t]{2}{*}{ In-plane } & Equation (4) & 0.2754 & - & 160 & & & 0.09 \\
\hline & & Equation (5) & 0.2747 & 0.0000160 & 82 & & & 0.05 \\
\hline
\end{tabular}

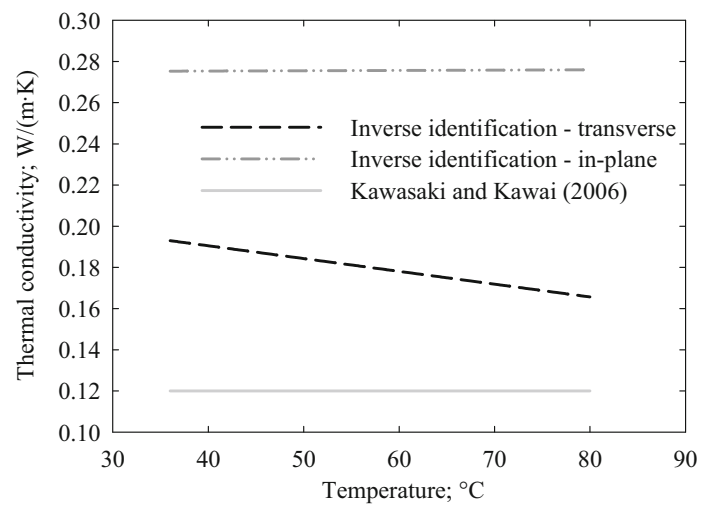

Fig. 3 Comparison of the thermal conductivity values for OSB as identified by the inverse modeling and reported by Kawasaki and Kawai (2006)

\subsection{Validation of identification}

The validation of the identified thermal conductivity values had to be limited for materials for which the thermal properties were also available in the literature. Therefore, two case studies of the validation were performed. The first one was made for OSB and the properties taken from Kawasaki and Kawai (2006), i.e. for a density of $660 \mathrm{~kg} / \mathrm{m}^{3}$, specific

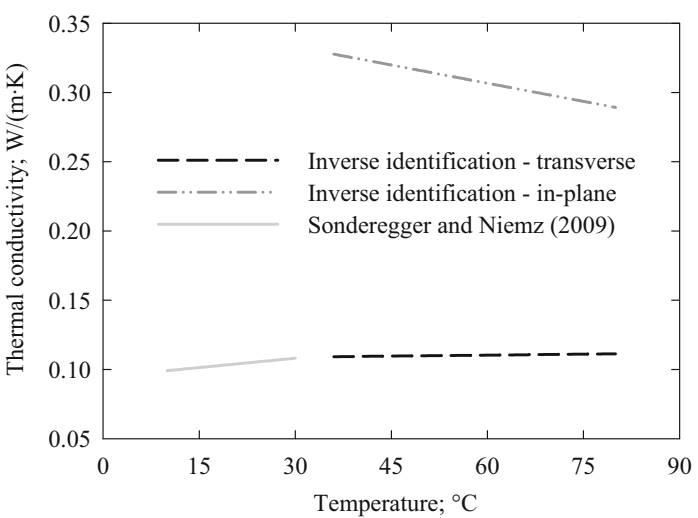

Fig. 4 Comparison of the thermal conductivity values for particleboard (PB1) as identified by the inverse modeling and reported by Sonderegger and Niemz (2009)

heat of $1500 \mathrm{~J} /(\mathrm{kg} \mathrm{K})$, and thermal conductivity equal to $0.12 \mathrm{~W} /(\mathrm{m} \mathrm{K})$ as determined at a temperature of $20.3{ }^{\circ} \mathrm{C}$. The OSB thermal properties of the present study consisted of the following values: density of $619 \mathrm{~kg} / \mathrm{m}^{3}$, specific heat of $1552 \mathrm{~J} /(\mathrm{kg} \mathrm{K})$ as reported by Czajkowski et al. (2016) and the identified in-plane and transverse thermal conductivity parameterized by Eq. (5) with coefficients given in Table 2. 
The second case study of validation was performed for particleboard being similar to PB1. The thermal properties data were obtained from Sonderegger and Niemz (2009) for particleboard of a density equal to $637 \mathrm{~kg} / \mathrm{m}^{3}$ and moisture content of $8.8 \%$. The thermal conductivity value of $0.1081 \mathrm{~W} /(\mathrm{m} \mathrm{K})$ was determined from the reported empirical relation for a temperature of $30{ }^{\circ} \mathrm{C}$. Sonderegger and Niemz (2009) did not provide information on the specific heat of the investigated particleboard, therefore the value of $1441 \mathrm{~J} /$ (kg K) was taken from TenWolde et al. (1988). The data were supplemented again by the set of properties obtained for PB1. The set consisted of a density of $634 \mathrm{~kg} / \mathrm{m}^{3}$, specific heat of $1441 \mathrm{~J} /(\mathrm{kg} \mathrm{K})$ as measured by Czajkowski et al. (2016) and the identified in-plane and transverse thermal conductivity parameterized by Eq. (5) with coefficients given in Table 2.

For both case studies of the validation the numerically obtained temperature changes in time were compared to the empirical data of experiments that were not used for the identification (Figs. 5, 6). In order to quantify the quality of the coefficient estimation, two errors were defined and calculated (Olek et al. 2003), i.e. the local in time relative error $e_{1}$ :

$$
\begin{gathered}
e_{1}\left(\mathbf{x}_{i}, \tau_{j}\right)=100 \frac{\left|t_{\exp }\left(\mathbf{x}_{i}, \tau_{j}\right)-t\left(\mathbf{x}_{i}, \tau_{j}\right)\right|}{t_{\exp }\left(\mathbf{x}_{i}, \tau_{j}\right)}, \\
i=1, \ldots, N S, j=1, \ldots, N T
\end{gathered}
$$

and the global in time relative error $e_{2}$ :

$$
\begin{gathered}
e_{2}\left(\mathbf{x}_{i}\right)=100 \frac{\sqrt{\sum_{j=1}^{N T}\left[t_{\exp }\left(\mathbf{x}_{i}, \tau_{j}\right)-t\left(\mathbf{x}_{i}, \tau_{j}\right)\right]^{2}}}{\sqrt{\sum_{j=1}^{N T} t_{\exp }\left(\mathbf{x}_{i}, \tau_{j}\right)^{2}}}, \\
i=1, \ldots, N S .
\end{gathered}
$$

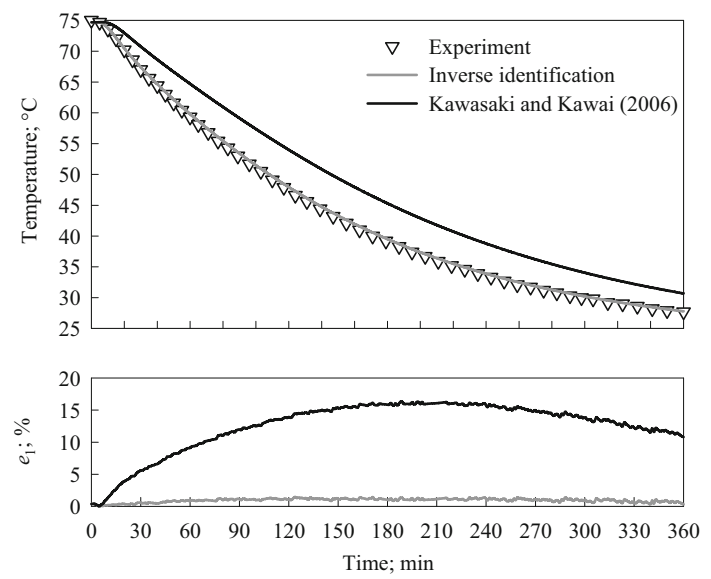

Fig. 5 Predicted temperature values as functions of time for identified thermal properties and empirical data reported by Kawasaki and Kawai (2006) compared to experimental data (upper plot), and the relative error $e_{1}$ of modeling (bottom plot). OSB, thermocouple \#3

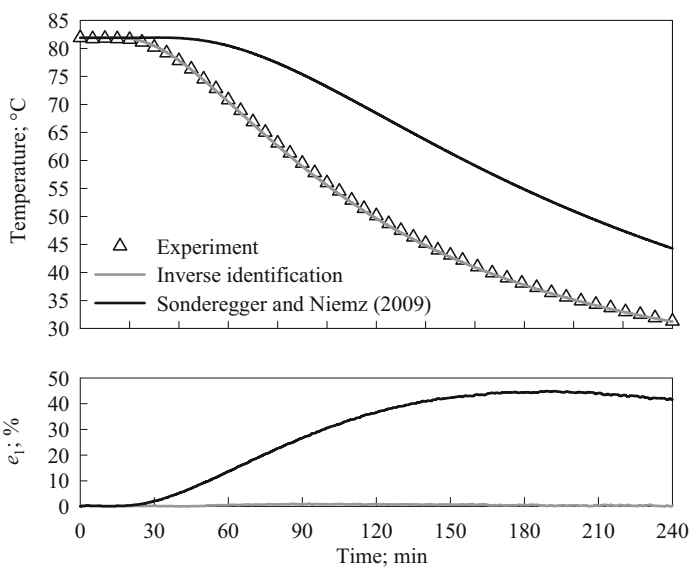

Fig. 6 Predicted temperature values as functions of time for identified thermal properties and empirical data reported by Sonderegger and Niemz (2009) compared to experimental data (upper plot), and the relative error $e_{1}$ of modeling (bottom plot). PB1, thermocouple \#1

The analysis of the local in time relative error $e_{1}$ (bottom plots in Figs. 5 and 6) and the global in time relative error $e_{2}$ (Table 3) led to the statement that the application of the data of thermal properties being available in the literature generated unacceptable inaccuracy of heat transfer modeling. It practically disparaged the data for predicting transient heat transfer in wood-based panels. The significant improvement of modeling was obtained when applying the measured values of specific heat (Czajkowski et al. 2016) as well as identified values of the in-plane and transverse thermal conductivity.

\section{Conclusion}

1. The application of the inverse method to the thermal conductivity identification enabled to account for anisotropy of the property. It was found for all analyzed wood-based panels that the in-plane thermal conductivity was significantly higher than the transverse one. Therefore, it was recommended to account for the anisotropy and use both in-plane and transverse thermal conductivity when modeling heat transfer in packages of wood-based panels.

2. The reported temperature influence on the thermal conductivity was not clear for the considered woodbased panels. It manifested in the different tendency of the influence, i.e. the thermal conductivity values were decreasing (e.g. transverse thermal conductivity for PB2 and PB3) or increasing (e.g. in-plane and transverse thermal conductivity values for LDF) with temperature for a given direction of heat transfer. Moreover, for some materials the influence was practically insignificant (i.e. PB1 and OSB), while 
Table 3 Values of the $e_{2}$ error for the analyzed empirical data options

\begin{tabular}{lllll}
\hline & Sensor code & \multicolumn{2}{l}{ Empirical data option } & \\
\cline { 3 - 5 } & & Kawasaki and Kawai (2006) & Sonderegger and Niemz (2009) & Inverse identification \\
\hline OSB & $\# 3$ & 11.46 & - & 0.92 \\
Particleboard (PB1) & $\# 1$ & - & 25.01 & 0.55 \\
\hline
\end{tabular}

for LDF the highest influence of temperature on the identified thermal conductivity was found.

3. The evaluation of the credibility of the thermal conductivity identification was effectively made by the implementation of the validation procedure. It was clearly shown that the thermal properties data available in the literature should not be used for modeling heat transfer in packages of wood-based panels, i.e. for heat transfer options in which in-plane and transverse heat conductivity had to be considered.

Acknowledgments The work was financially supported by the National Science Centre as the 2011/01/B/NZ9/03169 and 2011/01/ M/NZ9/00296 Research Grants.

Open Access This article is distributed under the terms of the Creative Commons Attribution 4.0 International License (http:// creativecommons.org/licenses/by/4.0/), which permits unrestricted use, distribution, and reproduction in any medium, provided you give appropriate credit to the original author(s) and the source, provide a link to the Creative Commons license, and indicate if changes were made.

\section{References}

Alifanov OM (1994) Inverse heat transfer problems. Springer-Verlag, Berlin

Asako Y, Kamikoga H, Nishimura H, Yamaguchi Y (2002) Effective thermal conductivity of compressed woods. Int J Heat Mass Transf 45:2243-2253

Bučar B, Straže A (2008) Determination of the thermal conductivity of wood by the hot plate method: the influence of morphological properties of fir wood (Abies alba Mill.) to the contact resistance. Holzforschung 62:362-367

Czajkowski Ł, Olek W, Weres J, Guzenda R (2016) Thermal properties of wood-based panels-specific heat determination. Wood Sci Technol Online first. doi:10.1007/s00226-016-0803-7

Gobbé C, Iserna S, Ladevie B (2004) Hot strip method: application to thermal characterisation of orthotropic media. Int J Therm Sci 43:951-958

Hammerschmidt U, Sabuga W (2000) Transient hot strip (THS) method: uncertainty assessment. Int J Thermophys 21:217-248

Huang C-H, Yan J-Y (1995) An inverse problem in simultaneously measuring temperature-dependent thermal conductivity and heat capacity. Int J Heat Mass Transf 38:3433-3441

Isakov V (1998) Inverse problems for partial differential equations. Springer-Verlag, New York
Kamke FA, Zylkowski SC (1989) Effect of wood-based panel characteristics on thermal conductivity. Forest Prod J 39(5):19-24

Kawasaki T, Kawai S (2006) Thermal insulation properties of woodbased sandwich panel for use as structural insulated walls and floors. J Wood Sci 52:75-83

Kim SK, Jung BS, Kim HJ, Lee WI (2003) Inverse estimation of thermophysical properties for anisotropic composite. Exp Therm Fluid Sci 27:697-704

Kirsch A (1996) An introduction to the mathematical theory of inverse problems. Springer-Verlag, New York

Kotlarewski NJ, Ozarska B, Gusamo BK (2014) Thermal conductivity of Papua New Guinea balsa wood measured using the needle probe procedure. BioResources 9:5784-5793

Lewis WC (1967) Thermal conductivity of wood-base fiber and particle panel materials. Research Paper FPL 77, Forest Product Laboratory, Madison, WI

Li KY, Fleischmann CM, Spearpoint MJ (2013) Determining thermal physical properties of pyrolyzing New Zealand medium density fibreboard (MDF). Chem Eng Sci 95:211-220

Monteau J-Y (2008) Estimation of thermal conductivity of sandwich bread using inverse method. J Food Eng 85:132-140

Olek W, Guzenda R (1995) Prediction of temperature changes in glued laminated beams. Holz Roh Werkst 53:249-252

Olek W, Weres J, Guzenda R (2003) Effects of thermal conductivity data on accuracy of modeling heat transfer in wood. Holzforschung 57:317-325

Schneider A, Engelhardt F (1977) Vergleichende Untersuchungen über die Wärmeleitfähigkeit von Holzspan- und Rindenplatten. (Comparative study on the thermal conductivity of particle boards and bark boards). Holz Roh Werkst 35:273-278 (In German)

Sonderegger W, Niemz P (2009) Thermal conductivity and water vapour transmission properties of wood-based materials. Eur J Wood Prod 67:313-321

Sonderegger W, Niemz P (2012) Thermal and moisture flux in soft fiberboards. Eur J Wood Prod 70:25-35

Speyer RF (1994) Thermal analysis of materials. Marcel Dekker Inc, New York

TenWolde A, McNatt JD, Krahn L (1988) Thermal properties of wood and wood panel products use in buildings. Report DOE/ USDA-21697/1 ORNL/Sub/87-21697/1, Forest Service, Forest Products Laboratory, Madison, WI

Vololonirina O, Coutand M, Perrin B (2014) Characterization of hygrothermal properties of wood-based products-impact of moisture content and temperature. Constr Build Mater 63:223-233

Ward RJ, Skaar C (1963) Specific heat and conductivity of particleboard as functions of temperature. Forest Prod $\mathbf{J}$ 13:31-38

Weres J, Olek W (2005) Inverse finite element analysis of technological processes of heat and mass transport in agricultural and forest products. Dry Technol 23:1737-1750 
Weres J, Olek W, Guzenda R (2000) Identification of mathematical model coefficients in the analysis of the heat and mass transport in wood. Dry Technol 18:1697-1708

Weres J, Olek W, Kujawa S (2009) Comparison of optimization algorithms for inverse FEA of heat and mass transport in biomaterials. J Theor Appl Mech 47:701-716
Zhou J, Zhou H, Hu C, Hu S (2013) Measurements of thermal and dielectric properties of medium density fiberboard with different moisture content. BioResources 8:4185-4192 